\title{
Analysis of the Job Preferences for Undergraduate Supply Chain Students
}

\author{
Michael S. Garver \\ Central Michigan University, 100 Smith Hall, Mt. Pleasant, MI 48859 \\ Email: garve1ms@cmich.edu \\ Sean P. Goffnett \\ Central Michigan University, 100 Smith Hall, Mt. Pleasant, MI 48859 \\ Email: goffn1sp@cmich.edu \\ Zachary Williams \\ Western Michigan University, 3210 Schneider Hall, Kalamazoo, MI 49008 \\ Email: williamszchy@gmail.com (Corresponding Author)
}

Richard L. Divine

Central Michigan University, 100 Smith Hall, Mt. Pleasant, MI 48859

Email: divin1r1@cmich.edu

Connor F. Davis

1676 Lakeshore Dr., Menasha, WI 54952

Email: davisfconnor@gmail.com

\begin{abstract}
The development of an effective recruitment strategy that attracts and secures entry-level logistics talent is essential to maintain corporate performance. To accomplish this, firms need to understand the attribute importance as well as the preferences of job applicants so that information can be used to develop more attractive job offers. To better understand job choice, choice based conjoint analysis was used. Key variables and their corresponding levels of interest in job choice were determined and presented to job seekers. Results of the current study indicate that for university undergraduate supply chain students, the three most important attributes used to evaluate entry level job positions are starting salary, fit with company culture and proximity of the worksite to friends and family. The results also show a preference for worksites located in the suburbs, in an office setting and for manufacturing firms. Below average preference was expressed for worksites in rural areas, those with lots of travel and firms in the retail and wholesale sectors. Implications for firms, educators and students are discussed.
\end{abstract}

Keywords: student job choice, talent management, conjoint analysis

\section{INTRODUCTION}

Talent recruitment and management in logistics and supply chain management (SCM) continues to be a critical issue (Maloni et al. 2016). Specifically, talent shortages are looming for the SCM discipline, which may have alarming and unwelcomed outcomes for organizations (Goffnett et al.
2013). As a result, there are continued calls for research into SCM career research (e.g., Autry \& Daugherty, 2003; Keller \& Ozment, 2009 Cottrill, 2010; Min \& Lambert, 2002; Williams et al., 2011).

Of the existing literature on SCM talent, much is singly focused on operational roles, such as truck drivers, or on managerial roles. This does leave a gap in knowledge on how younger professionals make job choice decisions. By developing an understanding of how specific job choice decisions are made by young professionals, employers can develop programs to better attract, and ultimately retain, talent. In this field, recruitment and retention are critical because (1) there is more demand for professionals in logistics and SCM than universities can supply, and (2) massive baby-boomer retirements are intensifying the talent shortage in logistics and SCM (Dubey \& Gunasekaran, 2015; Wolff et al., 2010). It is crucial that companies fill the talent gap with highly motivated and skilled professionals to remain successful and competitive (Goffnett et al., 2012; Daugherty et al., 2000; Richey et al., 2006; Tatham et al., 2017). Moreover, there is a need to better understand the critical drivers of logistics job selection and satisfaction (Goffnett et al., 2012; Hohenstein et al., 2014; Keller \& Ozment, 2009; Lynagh et al., 1999).

There is a need for additional research on logistics and SCM jobs that examines decision making factors in terms of what is most important in regard to job selection. This adds knowledge to the discipline and to job theory by presenting greater understanding of what factors young professionals (undergraduates) feel are most important in a SCM career 
and what factors may inhibit young professionals from accepting a job in logistics and SCM. Thus, the primary objectives of this exploratory study are to understand the job preferences for students entering the SCM field. To accomplish this, the paper is set forth as follows. A literature review on relevant theory is conducted. Next, research methodology used in the analysis are explained followed by a discussion of results. Implications for practitioners and educators are then examined. Lastly, conclusions including research limitations and suggestions for future research are provided.

\section{LITERATURE REVIEW}

The overarching objective of this exploratory research is to identify factors that influence specific job choices of individuals educated in logistics. To address this objective and the dearth of related research, the following presents the theoretical basis for this research shaped by a brief literature review concerning career theory, job theory, and careers in logistics and supply chain management.

\subsection{Career Theory}

Initial career research by pioneers such as Super (1957) defined career narrowly as an employer-employee relationship characterized by upward advancement and extrinsic reward, with age and organizational tenure often being used as proxies for career stage (Sullivan \& Baruch, 2009). Hall (1976) described career as an "individually perceived sequence of attitudes and behaviors associated with work-related experiences and activities over the span of a person's life" (p. 4). Sullivan and Baruch (2009) defined a career as "an individual's work-related and other relevant experiences, both inside and outside of organizations, that form a unique pattern over the individuals life span" ( $p$. 1543). Simply put, a career is an accumulation of work experiences in various roles over a period of time.

Early career theory was shaped on fixed stages of a vocation (e.g., Super, 1957), while later theory emphasizes boundaryless work experiences (e.g., Arthur \& Rousseau, 1996) and changes (e.g. Hall, 1996a \& 1996b). Arthur and Rousseau (1996) described the career as boundaryless giving various interpretations such as moving for family reasons or moving for the job itself or moving from one employer to another employer. The main idea is that a career is not dependent on one employer, nor does it have to subscribe to fixed path or location. Hall (1996a \& 1996b) uses the word protean to suggest that a career can change form seeing that the individual forms his or her own career based on individual skill and aspirations.

Career theory suggests that careers have both objective (physical) and subjective (psychological) components (Arthur, 1994; Arthur \& Rousseau, 1996; Evetts, 1992; Hall, 1976; Sullivan \& Arthur, 2006; Vardi, 1980). Subjective career components may include job choices, expectations, or perspectives one has over time in response to various roles. Evetts (1992), for example, described the subjective component of a career as 'transient' and 'constantly being changed' over time (p. 2). Career research, however, has focused on the objective career component, namely it being a sequence of jobs (Sullivan \& Arthur, 2006).

\subsection{Job Theory}

A major difference between a career and a job is the amount of time invested in the experience. A job consists of specific tasks that result in experience. Ilgen and Hollenbeck (1991) define a job as "a set of task elements grouped together under one job title and designed to be performed by a single individual" (p. 173). Jobs are objective as the tasks that make up a particular job are often specified in official job descriptions and standard work procedures. Tasks are typically well defined and structured in such a way that a given task may not change over an extended period of time (Ilgen \& Hollenbeck, 1991).

Early needs theorists, such as Maslow (1943), Herzberg et al. (1959), and Vroom (1964), emphasized the importance of understanding intrinsic and extrinsic job factors. Intrinsic factors include culture, employer reputation, job complexity, whereas extrinsic factors include salary and benefits, job security, and advancement opportunities. A number of theories relate to job selection such as social economic theory and Expectancy theory. However, this study is grounded in expectancy theory and job characteristics theory.

Expectancy theory, put forward by Victor Vroom (1964), emphasizes the motivating forces behind individual perceptions of the environment or situation and subsequent actions that manifest as a consequence of one's expectations. In addition, people will be motivated if they believe that greater effort will lead to greater performance that in turn will lead to their expected or desired outcome (i.e., reward). Vroom theorized that people choose a course of action based on perceptions and beliefs that are a consequence of their desire to enhance pleasure or satisfaction and to avoid pain or difficulty. The theory suggests that people will seek a job with certain expectations and if these expectations are met they will be attracted to the job and will be more inclined to accept the job and remain with the employer. Thus, Expectancy theory is applied in this study as a means to assess factors that may or may not influence a logistics job seeker.

Job characteristics theory (JCT), put forward by Hackman and Oldham (1976), provides an important framework for explaining the necessity for firms to define jobs with characteristics that motivate candidates to seek out job opportunities with the firm as well as incumbent employees to perform at high levels for the firm. JCT is still a popular approach to describing jobs in relation to employee attitudes and work outcomes. Hackman and Oldham theorized five core job characteristics that employers must consider: 1) skill variety, 2) task identity, 3) task significance, 4) autonomy, and 5) job related feedback (Oldham \& Hackman, 2010). These core characteristics, such as skills and identity, can make work attractive and meaningful. It holds that identifying important job characteristics is essential to attract and retain highperforming talent that is capable of enhancing overall company success. Firms that lack talent and struggle to acquire skilled and motivated professionals will be at a competitive disadvantage (Gibson et al., 2013).

A growing number of studies have been conducted that focus on job tasks and satisfaction. Job satisfaction is an emotional reaction to an individual's work experience, which may include feelings about specific tasks, compensation, and 
work environment (Chen et al., 2011; Rice, Gentile, \& McFarlin, 1991; Spector, 1985). Chen et al. (2011) explored varying levels of job satisfaction found in managerial and military groups over time and found job satisfaction is associated with worker intent to quit. Thus, it is imperative that professionals make the right job choice by making considerations for job and career factors that they feel are important and likely more satisfying in a job or career. Furthermore, theorists have argued that research is needed to explore the influence of contextual factors (e.g., industry, company culture) and personal factors (e.g., relationships, family) that will further shape career theory ( $\mathrm{Ng}$ et al., 2005; Sullivan \& Baruch, 2009). The main focus of this study is to investigate factors related to career/job choice as indicated by individuals who are educated in logistics and supply chain management.

\subsection{Job and Career Research in SCM}

There is a growing body of research in the discipline that examines careers and job selection and retention of logistics and SCM professionals. Most studies in this area focus on either labor (e.g., truck drivers, pickers) or leadership (e.g., supervisors, managers, executives). In terms of labor, it is widely known that trucking has high driver turnover and is experiencing a severe driver shortage to this day. Keller (2002) argues that providing higher pay, more time at home, and improved dispatching can reduce driver turnover. Autry and Daugherty (2003) studied warehouse workers and found supervisor fit and company characteristics (compensation, culture, procedures) have a significant influence on warehouse worker job satisfaction.

In terms of management and leadership in logistics, Lynagh et al. (1996) found that $69 \%$ of women and $85 \%$ of men were satisfied, if not very satisfied, with their logistics job. Cook and Gibson (2000) studied 3PL junior managers and found retention rates decreased significantly over the first three years of employment with a mean retention rate of $67 \%$. Junior manager turnover was due to a number of reasons, such as receiving better pay, disliking their current job location, and deeming that the corporate culture was not a good fit. Daugherty et al. (2000) argued that logistics and SCM companies can increase manager retention through compensation, professional development opportunities, and rewarding managers for problem solving and decision making. Likely the most seminal research in this area comes from LeMay and colleagues (1999), who researched a diverse set of careers and explored growth and development among logistics personnel.

Only a few studies exist that examine talent supply in the logistics industry, specifically the perceptions of new graduates and young logistics professionals. Gibson and Cook (2003) studied logistics undergraduate students and what they valued in a position in logistics and SCM, with the results suggesting that opportunity for advancement, positive company culture, salary offered, job security, and training are highly valued. Knemeyer and Murphy (2004) conducted a similar study and found marketing undergraduates valued a number of things about possible logistics careers such as challenge, opportunities for advancement, and gender friendliness.

Recently, a renewed interest on human resources in supply chain management has developed. Specifically, researchers have implemented the idea of factor market structure in supply chain management. In simple terms, factor market rivalry is increased competition for interfirm resources. One of the identified factor market rivalries in supply chain management is human capital (Ellram et al., 2013; Ralston et al., 2017).

Factor market rivalry influences the undergraduate choice in supply chain careers. It is likely that undergraduate students have a multitude of choices upon entering a career path. Given that students do not yet have deep-rooted skills that will drive them into a career path, the war for supply chain talent grows large. As a result, organizations are continually battling for human talent, i.e., the market rivalry. Understanding the choices that student's make toward a supply chain oriented career has the potential to assist in attracting talent within the market rivalries.

To summarize, the competition among firms to acquire supply chain talent continues to be very intense as the demand for qualified professionals exceeds the available supply. A number of job-related factors have been identified in the literature that impact the recruitment and acquisition of supply chain talent, but it is unclear which of these are relevant to the market for undergraduate university supply chain students and what the relative importance of these factors might be.

\section{RESEARCH METHOD}

A choice-based conjoint analysis survey was delivered to a sampling frame of logistics undergraduate students to answer two important research questions:

- What employment attributes are most important to logistics undergraduate students who are near entering the SCM workforce?

- What are the preferences for the different levels of job choice?

\subsection{Research Method: Choice Based Conjoint Analysis}

The primary purpose of this study was to examine how logistics undergraduate students chose full time logistics positions. The researchers chose choice-based conjoint analysis as the research method for this study because it was the best fit with the research context and fulfills the research objectives (Voss et al., 2009).

Conjoint analysis has widely been implemented as a prominent research tool in the marketing academic literature over the last 40 years (Green and Srivstan, 1978). As a research method, conjoint analysis has many unique advantages. For example, conjoint analysis has the survey respondent simply makes choices, very similar to how respondents make choices in real life. Respondents face difficult tradeoffs in everyday choices, and conjoint analysis includes these difficult tradeoffs in the choices presented to respondents (Voss et al., 2009). For example, if the customer wants faster service, then they will most likely have to choose faster service at a higher cost.

While marketing academics have used conjoint analysis in many different applications, recently, logistics and supply chain management researchers are calling for increased usage of conjoint analysis research methods (Garver et al., 2012). Recently, academic researchers have 
used conjoint analysis to understand how potential employees make choices about potential job openings. For example, Yasmin et al. (2016) employed conjoint analysis to examine job preferences for executives in Bangladesh. In a similar manner, Meyerding (2017) implemented conjoint analysis to examine job preferences for agricultural students in Germany.

In a choice based conjoint analysis study, participants are given three or four competitive alternatives in every question (Garver et al., 2012). While the same attributes are included in each competitive alternative, the levels of performance for each of the attributes will vary in each question (Voss et al., 2009). Respondents choose the one competitive alternative they most prefer in each question (Agarwal et al., 2015). Choice based conjoint analysis has demonstrated the highest predictive capabilities and is also perceived as the most realistic method in that it closely resembles how respondents actually make choices in the real world (Garver et al., 2012). Choice-based conjoint analysis is the most popular form of conjoint analysis today, and it excels at examining how respondents make choices, which is the purpose of this study (Garver et al., 2012).

\subsection{Conjoint Analysis Attributes and Levels of Choice}

After choosing the conjoint analysis method, the next step is to identify the relevant attributes and their corresponding levels of performance for the choices (de Bekker-Grob et al., 2012). The first step in identifying relevant attributes and levels for this study was a thorough literature review. All of the attributes for this study were first identified in the literature as important factors for selecting a job. For example, salary, work environment, type of firm, type of job, fit with company culture, and distance from home were all discovered in the literature review.

Then, in-depth interviews were conducted with logistics undergraduate students, who were members of a University honors organization. These discussions focused on understanding the process of entry level job selection along with the different attributes and their corresponding levels of performance that were desired in a full-time logistics position. Additionally, questions and discussions focused on the job search experiences and preferences. These discussions also included student reasons for declining full-time offers from companies. These in-depth interviews confirmed the attributes identified in the literature as well as finalizing their wording so that logistics undergraduate students clearly understood their meaning.

Finally, the researchers consulted with industry experts and professors who have had experience with recruiting and placing undergraduate logistics students in full-time logistics positions. As a result of the literature review, in-depth interviews with logistics undergraduate students, and discussions with industry experts, a list of relevant attributes and their corresponding levels of performance was developed for this conjoint analysis study.

The literature review for the attributes selected for this study will now be discussed.

\subsubsection{Salary}

Salary is widely evaluated in many areas of research, including studies on job selection and student job choice.
Montgomery and Ramus (2011) use salary in their conjoint analysis of job selection. The results suggest that salary is of key importance in job selection. Jin et al. (2014) find that higher salary is expected by students when jobs are outside of their home range. Salary was also shown to be a critical variable of influence in additional student job choice studies (e.g., Sedighi and Loosemore, 2012).

Within the supply chain management literature, salary has also been a key variable of interest. For example, in a comprehensive review of human resource issues in supply chain management, salary was identified as critical component of prior research (Hohenstein et al., 2014). Moreover, within the supply chain career and job choice literature, salary has been identified as a critical attribute for employees (e.g., Cook et al., 2009; Goffnett et al., 2012; Knemeyer and Murphy, 2004; Goffnett et al., 2013; Gibson and Cook, 2003; Garver et al., 2017).

\subsubsection{Type of Firms}

Within a wide variety of careers, there are often different types of organizations to pursue employment. For example, in a study of accounting students job choice, Butler et al. (2002) evaluated the firm type when studying job choice. In their research, accounting job seekers were presented with different firm types, such as the choice between public-sector accounting firms (e.g., the "big six") or private accounting firms (non-public firms). Similarly, Bundy and Norris (1992) studied accounting students' perceptions of job choice. In the study, the researchers had students rate the importance of various types of work, including public auditing, internal auditing, and governmental auditing, among others. Importantly, different types of firms have also been a key decision variable in the decision making process. Iacovou et al. (2004) also find type of firm to be of importance for students during the job selection process. In the information technology (IT) area, Thatcher (2002) found strong differences among student jobseekers with regard to preferences for different firm types (e.g., in-house IT department, IT consultant, or IT vendor) and that students with different firm-type preferences varied significantly in what job criteria was important to them. Finally, Burman et al. (2008) found that employer attractiveness to job seekers was strongly impacted by the type of industry a firm competes in.

In supply chain management studies, distinct collections of firms are often used for classification purposes. These groupings often include firms that make (manufacturers), firms that move (transportation providers), and firms that sell (retailers). However, given differences in backgrounds, experiences, and career goals, students may prefer to work at certain types of SCM firms more than others.

\subsubsection{Work Environment}

Various studies have highlighted the importance of work environment on job choice. Butler et al. (2002) also used work environment as a key variable of interest in their study on job choice. Montgomery and Ramus (2011) used work type of position, which was operationalized as management vs. non-management positions in their conjoint analysis of job selection. Finally, work environment was highlighted as a critical factor in job choice for undergraduate supply chain students (Garver et al., 2017). 


\subsubsection{Location}

The location of the job has been demonstrated as a key variable of interest in the job choice process. Montgomery and Ramus (2011) used geographic area in their conjoint analysis of job selection. This finding confirmed that location was a critical selection factor in their study. The authors also noted that several factors, including location, had consistent and strong importance in job selection over time. Additionally, Butler et al. (2002) also used city size as a key variable of interest in their study on job choice. Philips and Philips (1998) also found both location and region to be key attributes in job choice.

Jin, Mjelde, and Litzenberg (2014) included size of location in an experiment. The researchers find that size had "little-to-no effect" (pg. 318) on the job preference decision. Additionally, location was identified as a key variable of interest in job choice of supply chain students (Cook et al., 2009; Goffnett et al., 2013; Garver et al., 2017). Cook et al. (2009) found that a large percentage of undergraduate supply chain job seekers had a strong preference for specific cities, states, and regions when selecting full-time job opportunities. Additionally, undesirable locations have been shown to be a strong predictor of turnover among supply chain personnel (Gibson et al., 2013).

\subsubsection{Distance from Home}

Job choice can be difficult for undergraduates, especially when that involves moving a long distance from what the student considers home. For example, Jin, et al. (2014) included distance as an attribute in their evaluation of student job choice. The findings of the experiment indicated that undergraduates have a propensity to choose jobs within their home state. Furthermore, if a student were to choose a job outside of what they considered home, additional financial compensation was needed (i.e., higher starting salary).

Distance has been highlighted in supply chain research as well. In their study of supply chain students, Gibson and Cook (2003) found location flexibility and a high willingness to relocate an opportunity among supply chain students. Additionally, Cook et al. (2009) found that many undergraduate supply chain job seekers had strong desires for specific geographic locations due to family, friend, and familiarity.

\subsubsection{Company Culture}

Sedighi and Loosemore (2012) found that one of the most critical factors in job choice is a relaxed workplace, as identified by students. Additional criteria associated with the notion of organization culture were also shown as important: recognition of contribution, training programs, co-worker values, and flexible hours. Similarly, Gokuladas (2010) found reputation, (i.e., culture and image) to be a strong predictor of job choice. Additionally, Goffnett et al. (2012) identified culture as a critical influencer of satisfaction in the logistics/supply chain career. Garver et al. (2017) found culture to be the third most important factor for entry-level supply chain job choice. In a survey of undergraduate supply chain students, Gibson and Cook (2003) found fit with culture to be a substantial attribute of job selection, as did Cook et al. (2009). Unfortunately, negative cultures have been identified as an issue for supply chain personnel turnover (Gibson et al., 2013). Montgomery and Ramus
(2011) also used culture in their conjoint analysis of job selection.

Based on the literature review, in-depth interviews with logistics undergraduate students, and discussion with industry experts, the researchers identified and defined the relevant attributes and their corresponding levels of performance for this research study, which can be viewed below (the attributes are stated first, while the levels of performance are indented under the attribute).

- Starting Salary

$\begin{array}{ll}\circ & \$ 60,000 \\ \circ & \$ 50,000 \\ \circ & \$ 40,000\end{array}$

- Type of Firm

- Manufacturer

- 3PL / Transportation Carrier

- Retailer / Wholesaler

- Work Environment

O Office

- Field / Plant

- Road Warrior

- Location

$$
\begin{array}{ll}
\circ & \text { Suburbs } \\
\circ & \text { Big city } \\
\circ & \text { Rural }
\end{array}
$$

- Distance from home/family

$$
\begin{array}{cl}
\circ & 1 \text { hour drive away } \\
\circ & 4 \text { hour drive away } \\
\circ & \text { Air travel required }
\end{array}
$$

- Fit with company culture

$$
\begin{array}{ll}
\circ & \text { Yes } \\
\circ & \text { No }
\end{array}
$$

These attributes and their corresponding levels were entered into an experimental design, which guided the creation of the choice-based conjoint analysis survey questions (Agarwal et al. 2015; Gilbride and Allenby 2004). For each conjoint question, three full-time job alternatives were available to be selected. Each question asked, "Please select a full-time job. If these were your only options, which job would you choose?" After the initial survey was created, various professors and logistics students offered suggestions for improving the survey. After a number of rounds of receiving feedback and making survey modifications, a draft of the survey was then tested on a convenience sample of logistics undergraduate students. After pre-testing the survey, a few changes were implemented. These changes were minor in nature, and were mostly concerned with the wording of certain survey questions as well as the placement of these questions in the survey. Once the survey was modified and completed, the final survey was posted on a secure, password protected web site and administered to a sample of logistics undergraduate students.

\subsection{Data Collection}

The email invitation was sent to the entire sampling frame, which included 338 undergraduate students who were majoring in marketing and / or logistics at a large Midwestern University. Data collection took place during both the Fall (October) and Spring (February) semesters. 206 undergraduate students responded to the survey for a response rate of $61 \%$. Because students were either a marketing or logistics major, the researchers employed a 
screening question which asked students if they were more interested in logistics or a marketing full-time job. Only those students who were interested in pursuing a logistics full-time job were included in this study. This resulted in survey responses from 84 logistics undergraduate students. After data cleaning, a number of surveys were deemed to be incomplete or possess low quality responses, as detected by a number of quality checks that were undertaken to ensure quality responses from the sample. The final sample resulted in 71 quality responses. Our analysis for non-response bias suggests that there were no significant differences between early and late respondents (Armstrong and Overton 1977).

\section{RESEARCH RESULTS: STATISTICAL ANALYSIS}

In this section, sample characteristics will be discussed first. Then, the researchers employed Hierarchical Bayes to analyze the choice data, which provided overall attribute importance scores as well as preference scores for each of the corresponding levels.

\subsection{Sample Demographics}

Concerning this sample of logistics undergraduate students, each member of the sample is a logistics major, with $86 \%$ of the sample also being a marketing major. Yet, $100 \%$ of the sample is interested in pursuing a full time logistics job in the near future after graduation. In addition, $79 \%$ of the sample were male, while only $21 \%$ of the sample were female. $69 \%$ of the sample had an internship prior to taking this survey.

\subsection{Conjoint Analysis Results: Importance of Attributes}

When undergraduate logistics students are deciding which logistics full-time job to choose, what attributes are most important in driving that decision? This analysis will now answer this question. Please note that when interpreting conjoint analysis results for attribute importance, the higher the score, the more important the attribute is to their choice. In addition, these attribute importance scores display relative importance to each other, with all of the importance scores summing to 100 points (Garver et al. 2012).

Examining Table 1, the researchers concluded that there are two different tiers of attribute importance, meaning that the top three most important attributes have relatively similar importance scores. Likewise, the three least important attributes also have relatively similar importance scores. For example, "Starting salary" (23.3) is the most important attribute, followed closely by "Distance from home/family" (21.7), and then "Fit with company culture" (20.4). In summary, receiving a competitive starting salary, being close to home and family, and fitting in with the company culture is most important to undergraduate logistics students in this sample. These three attributes account for more than $65 \%$ of the importance when undergraduate students choose a full-time logistics position.

The second tier of attribute importance includes the "work environment" (12.6), the "location" of the firm (11.2), and "type of firm" (10.8). These three attributes are important to an undergraduate students' choice for a fulltime logistics position, yet they are significantly less important than the "starting salary," "distance from home," and "fit with company culture."

\subsection{Conjoint Analysis Results: Preference Scores for Levels}

Preference scores are zero-based numbers, meaning that 0 represents average preference, while a positive preference score represents above average preference, and a negative preference score represents below average preference (Garver et al. 2012). Examining results in Table $\mathbf{2}$, the preferences scores for the levels of performance are interesting. As expected, logistics undergraduate students place above average preference for $\$ 60,000$ as a starting salary (69.6). A $\$ 50,000$ starting salary (-3.1) has slightly below average preference and a $\$ 40,000$ starting salary (66.6) has below average preference.

Concerning distance from home and family, logistics undergraduate students place well above average preference on living within 1 hour of their family (71.1). Logistics undergraduate students place below average preference for the remaining levels: Being a 4 hour drive away from home $(-34.4)$ or requiring air travel $(-36.7)$ to visit home. Fitting in with the company culture (60.4) has above average preference, whereas not fitting in with the company culture (-60.4) has below average preference. "Fitting-in" is highly preferred by these students.

Concerning the work environment, the office setting (18.1) is most preferred followed by the field / plant setting (12.6), with both of these levels having above average preference. Logistics undergraduate students place below average preference on being a road warrior (-17.6), a setting that would require a great deal of travel. Concerning the location of their full-time logistics position, logistics undergraduate students place above average preference on living in the suburbs (11.4) and living in a big city (6.4). The preference scores are relatively close for living in the suburbs and in a big city. In contrast, living in a rural setting (-17.6) has below average preference.

Finally, in regard to the type of firm, logistics undergraduate students place the most preference on working for a manufacturer (9.6) followed closely by a 3PL or transportation carrier (5.9), with both of these levels having slightly above average preference. Working for a retailer or wholesaler $(-15.5)$ has below average preference 
Table 1 Attribute Importance

\begin{tabular}{|c|c|}
\hline Attributes & Importance Score \\
\hline Starting Salary & 23.3 \\
\hline Distance from home/family & 21.7 \\
\hline Fit with company culture & 20.4 \\
\hline Work Environment & 12.6 \\
\hline Location & 11.2 \\
\hline Type of Firm & 10.8 \\
\hline
\end{tabular}

Table 2 Preferences Scores for the Levels

\begin{tabular}{|c|c|c|}
\hline Attributes & Levels & Preference Score \\
\hline \multicolumn{3}{|l|}{ Starting Salary } \\
\hline & $\$ 60,000$ & 69.6 \\
\hline & $\$ 50,000$ & -3.1 \\
\hline & $\$ 40,000$ & -66.6 \\
\hline \multicolumn{3}{|c|}{ Distance from home/family } \\
\hline & 1 hour drive away & 71.1 \\
\hline & 4 hour drive away & -34.4 \\
\hline & Air travel required & -36.7 \\
\hline \multicolumn{3}{|c|}{ Fit with company culture } \\
\hline & Yes & 60.4 \\
\hline & No & -60.4 \\
\hline \multicolumn{3}{|l|}{ Work Environment } \\
\hline & Office & 18.1 \\
\hline & Field / Plant & 12.6 \\
\hline & Road Warrior & -30.7 \\
\hline \multicolumn{3}{|l|}{ Location } \\
\hline & Suburbs & 11.4 \\
\hline & Big city & 6.2 \\
\hline & Rural & -17.6 \\
\hline \multicolumn{3}{|l|}{ Type of Firm } \\
\hline & Manufacturer & 9.6 \\
\hline & 3PL / Transportation Carrier & 5.9 \\
\hline & Retailer / Wholesaler & -15.5 \\
\hline
\end{tabular}

To sum up undergraduate student preferences for a full time logistics position, they would like a logistics position where they earn $\$ 60,000$ a year living in the suburbs within an hour's drive from their family. They want to fit in with company culture and to work in an office setting for a manufacturing company.

\section{IMPLICATIONS AND SUMMARY}

The results of the conjoint analysis indicate the three most important factors in determining student preference for a logistics position are starting salary, distance from home/family and fit with company culture. While the positioning of starting salary as the number one criterion is not unexpected, what might be is how close in importance the other two factors are. This suggests that recruiting talent is not just a function of money, but companies can strategically leverage the other two criteria to attract quality applicants to their organization without entering into costly bidding wars. Companies who recruit in their own geographic area may be able to attract quality applicants at lower starting salaries. Rather than trying to mitigate the negative effects and uncertainty in the minds of out-of-region applicants associated with relocation to an unfamiliar place, location can be positioned as a positive to those job applicants who wish to remain in their home area. Local and regional recruiting can reduce the travel-related search and 
relocation expenses associated with national or international searches. Turnover should also be reduced as regional hires are likely to be more integrated into the community and local culture, and thus, less likely to be homesick and leave the organization to pursue career opportunities closer to their family or in the comfort/familiarity of their home region.

The importance of fit with corporate culture also suggests a number of implications. Developing a positive corporate culture can be monetized by allowing the organization to attract better talent at a lower cost/starting salary. Positive culture should improve productivity and decrease turnover. Employees who work in a supportive environment are able to focus on their job tasks rather than on office politics or interpersonal squabbles, and may be less likely to become disgruntled and leave. However, developing a positive culture is easier said than done. Some organizations believe that a culture that may be less preferred by college applicants may be instrumental to their success in the marketplace. Some organizations adopt a highly competitive culture that may be off-putting to those seeking a more team-oriented environment. Others may operate in a more formal corporate environment, employing more topdown hierarchical governance and less autonomy for employees. If organizations believe their culture enhances performance, but are less likely to appeal to many applicants, then they may want to: 1) invest in personality testing to identify applicants who best fit their philosophy, 2) target those who place less importance on culture as a job selection criterion or 3) compensate for this relative competitive weakness with higher starting salaries in order to attract and retain quality applicants.

Finally, a few employer demographic factors emerged as preferred criteria for college students entering the job market. Positions that offer applicants an opportunity to work in an office setting, in the suburbs and/or in the manufacturing sector should emphasize these characteristics in recruiting communications. These attributes enhance the value of the job opportunity to logistics students entering the market.

Interestingly, low or negative preference was expressed for high-travel positions, rural locations and the retail and wholesale sectors. This insight provides interesting challenges. First, job opportunities that feature any of these characteristics may need to offer higher salaries in order to entice high-quality candidates. Second, firms may need to devote additional resources to applicant screening in order to better identify potential employees who actually prefer these characteristics or who place a much greater importance on the other job-related criteria. For example, high-travel positions may need to seek applicants that are experienced travelers or moved a lot during childhood.

Unfortunately for operational logistics, these results present issues. Often times, transportation terminals, distribution centers, and in general, the operations of the supply chain reside in remote areas. This presents a formidable task for those seeking talent. This is also an area of opportunity for academics. Providing students with a clear understanding that operations often are in remote locations can be paramount in realistic job preview. Further, organizations seeking talent in remote locations may want to seek talent from the nearest college, university, and community college. Lastly, organizations may find opportunity in seeking out talent with military backgrounds as this under-utilized segment of the workforce may already have an appreciation for the issues noted above.

Retailers and wholesalers also face challenges among entry-level job seekers. Retailers can utilize several factors to mitigate the low preference. First, highlighting the rapid and technological change in the industry may draw interest from Millennials. Second, clearly delineating the role for the position may be critical. In other words, specifically highlighting the role of an inventory analyst at the corporate office may be more appealing to an entry-level job seeker. When promoting positions as a retailer, job seekers may presume this includes "in-store" activities, which may not be appealing to logistics job seekers. Wholesalers/distributors may be have difficulty in promoting opportunity among entry-level job seekers. As an alternative approach, these organizations may want to focus on internships, where they can draw in young talent and ideally retain that talent postgraduation. Further, these organizations may find value in seeking experienced hires, as opposed to going "head-tohead" with manufacturers on a college campus.

\subsection{Research Limitations}

As with any research study, there are research limitations with this research study. First, the sample size of 71 is low. While the sample size is above the minimum threshold and adequate, a larger sample size would deliver more confidence to the research community. Furthermore, the logistics undergraduate students all come from one Midwestern university. Future research should try to replicate this study looking across a number of different universities who have logistics undergraduate programs.

As with any research method, choice based conjoint analysis has limitations that are important to note. The most significant limitation is the required time and effort that respondents have to expend to answer the questions. Additionally, respondents may also feel that the choices are redundant. As a result, it is easy to "burn out" respondents, with the result being low quality responses. There are quality measures delivered with choice based conjoint analysis results that can detect low quality responses, but it is still a limitation.

Choice based conjoint analysis choice assumes that respondents use a compensatory decision-making process. However, this assumption has been called into question (Hauser et al., 2009). If respondents do indeed use a noncompensatory decision-making process, then this is a major limitation of choice based conjoint analysis studies.

Choice based conjoint analysis shares the same limitation as other stated research techniques, where respondents overstate or understate the importance of some attributes relative to actual decisions (Garver 2003). For example, price is often underrated in a research context when compared to spending money in an actual purchase. More specific to this study, compensation maybe underrated in this study as well. Even with these limitations, the researchers have confidence in the findings.

\subsection{Future Research}

Future research should replicate this study across a number of logistics programs at universities across the country. Conducting this research would result in larger sample sizes as well as getting a more accurate, valid, and 
reliable picture of how logistics undergraduate programs across the country perceive choosing full-time logistics positions. A larger sample size would also allow researchers to segment undergraduate logistics student on their preferences.

Garver et al. (2012) suggest that logistics researchers should employ adaptive conjoint analysis for situations where respondents might demonstrate choices that possess "must have" or "must avoid" performance levels, similar to lexicographic decision making models. For example, it is not hard to imagine that certain logistics students would not accept job offers if the salary is below a certain level. Likewise, certain logistics students might not accept job offers that are too far from home, or if the job offer is not aligned with their primary interests. In these situations, adaptive conjoint analysis might be a more appropriate research method and future research should implement adaptive conjoint analysis in logistics.

This paper focused on respondents choosing a logistics employment opportunity, yet future research needs to address retention of these logistics employees. With employee satisfaction research, statistically inferred analysis of the attributes (i.e., independent variables) to determine the importance of these attributes is common practice. Yet, recent academic research in this area suggests that this analysis is often skewed and biased due to high levels of multicollinearity (Garver and Willams, 2017). Correlated components regression analysis and relative weight regression analysis are two research techniques that are designed to overcome the problems of multicollinearity, yet scant research attention in logistics has been devoted to these research techniques. Future research in logistics needs to address how correlated components regression analysis and relative weight regression analysis can be used by logistics researchers to improve the validity of theory testing as well as address the needs of logistics practitioners in conducting statistically inferred attribute importance analysis for customer and employee satisfaction research.

Academic research in logistics and supply chain management needs to examine new research methods to examine and test theoretical models. As with many fields of study, academic researchers tend to overly rely on popular research methods in their discipline. Academic research needs to examine new or underutilize research methods that could be used to examine logistics and supply chain management theory as well as to examine practical problems faced by logistics and supply chain management professionals.

\section{REFERENCES}

Agarwal, J., DeSarbo, W., Malhotra, N., and Rao, V. (2015). An Interdisciplinary Review of Research in Conjoint Analysis: Recent Developments and Directions for Future Research. Customer Needs and Solutions, 2 (1), pp. 19-40.

Armstrong, S. and Overton, T. (1977). Estimating nonresponse bias in mail surveys. Journal of Marketing Research, 14 (3), pp. 396-402.

Arthur, M. B. 1994. The boundaryless career: A new perspective for organizational inquiry. Journal of Organizational Behavior, 15 (4), pp. 295-306.

Arthur, M. B., and Rousseau, D. M. (1996), The Boundaryless Career: A New Employment Principle for a New Organizational Era, Oxford University Press, New York, NY.
Autry, C. W., and Daugherty, P. J. (2003). Warehouse Operations Employees: Linking Person-Organization Fit, Job Satisfaction and Coping Responses. Journal of Business Logistics, 24 (1), pp. 171-197.

Bundy, P., and Norris, D. (1992). What accounting students consider important in the job selection process. Journal of Applied Business Research, 8(2), pp. 1-6.

Burman, C., Schaefer, K., and Maloney P., (2008). Industry impacts: Its impact on the brand image of potential employees. Journal of Brand Management, 15 (3), pp. 157-196.

Butler, S. A., Sanders, D. E., and Whitecotton, S. M. (2000). Student and recruiter insights on the importance of job attributes. Journal of Managerial Issues, 12 (3), pp. 337-351.

Chen, G., Ployhart, R. E., Thomas, H. C., Anderson, N., and Bliese, P. D. (2011), The Power of Momentum: A New Model of Dynamic Relationships between Job Satisfaction Change and Turnover Intentions. Academy of Management Journal, 54 (1), pp. 159-181.

Cook, R. L., and Gibson, B. J. (2000), Management Development and Retention Programs in U.S. Third-Party Logistics Firms. Journal of Transportation Management, 12 (1), pp. 1-18.

Cook, Robert L., Brian J. Gibson, and Williams, Z. (2009), Logistics and Supply Chain Job Placement: The 2007 Perspective. Journal of Transportation Management, 19 (2), pp. 1-22.

Daugherty, P. J., Lusch, R. F., Myers, M. B., and Griffith, D. A. (2000). Linking compensation and retention. Supply Chain Management Review, 4 (3), pp. 64-72.

De Bekker-Grob, E. W., Ryan, M., and Gerard, K. (2012). Discrete choice experiments in health economics: A review of the literature. Health Economics, 21 (2), pp. 145-172.

Dubey, R., and Gunasekaran, A. (2015). Shortage of sustainable supply chain talent: an industrial training framework. Industrial and Commercial Training, 47 (2), pp. 86-94.

Ellram, L.M., Tate, W.L., and Feitzinger, E.G. (2013). FactorMarket Rivalry and Competition for Supply Chain Resources. Journal of Supply Chain Management, 49 (1), pp. 29-46.

Evetts, J. (1992). Dimensions of career: Avoiding reification in the analysis of change. Sociology, 26 (1), pp. 1-21.

Garver, M. (2003). Customer-Driven improvement model: Best practices in identifying improvement opportunities. Industrial Marketing Management, 32 (6), pp. 455-466.

Garver, M. (2016). Examining carrier selection with situational choice models. Transportation Journal, 5 (2), pp. 224-236.

Garver, M.S. and Williams, Z. (2017). Improving the validity of theory testing in logistics research using correlated components regression. International Journal of Logistics: Research and Applications (in press; available online), pp. 115.

Garver, M., Williams, Z., Taylor S., and Wynne, W., (2012). Modelling choice in logistics: A managerial guide and application. International Journal of Physical Distribution \& Logistics Management, 42 (2), pp. 128-151.

Garver, M., Williams, Z., and LeMay S. (2010). Measuring the importance of attributes in logistics research. International Journal of Logistics Management, 21 (1), pp. 22-44.

Gibson, B. J., and Cook, R. L. (2003), Entry-level logistics management hiring issues. The International Journal of Logistics Management, 14 (1), pp. 121-134.

Gibson, B., Goffnett, S. P., Williams, Z., Cook, R. L. (Winter 2014). SCM Talent Development Module 3: The Advance Process (pp. 1-40). Lombard, IL: Council of Supply Chain Management Professionals (CSCMP).

Gilbride, T., and Allenby, G. M. (2004). A choice model with conjunctive, disjunctive, and compensatory screening rules. Marketing Science, 23 (3), pp. 391-406.

Goffnett, S.P., Cook, R.L., Williams, Z. and Gibson, B.J., (2012). Understanding satisfaction with supply chain management careers: an exploratory study. The International Journal of Logistics Management, 23 (1), pp. 135-158. 
Goffnett, S. P., Divine, R. L., Williams, Z., and Cook, R. L. (2013). Understanding the impact of extrinsic and intrinsic SCM career choice factors on career satisfaction. Journal of Operations \& Supply Chain Management, 6 (1), pp. 122-138.

Gokuladas, V. K. (2010). Factors that influence first-career choice of undergraduate engineers in software services companies. Career Development International, 15 (2), pp. 144-165.

Hackman, J. R., and Oldman, G.R. (1976). Motivation through the design of work: Test of a theory. Organizational Behavior and Human Performance, 16 (2), pp. 250-279.

Hall, D. T. (1976), Careers in Organizations, Forseman, Glenview, IL.

Hall, D. T. (1996a), The career is dead-long live the career: A relational approach to careers, Jossey-Bass, San Francisco, CA.

Hall, D. T. (1996b). Protean careers of the $21^{\text {st }}$ century. Academy of Management Executive, 10 (4), pp. 8-16.

Hauser, J.R., Ding, M., and Gaskin, S.P. (2009). Non-compensatory (and compensatory) models of consideration-set decisions. In Proceedings of Sawtooth Software Conference, Del Ray Beach, FL.

Herzberg, F., Mausner, B., and Snyderman, B. (1959). The Motivation to Work, Wiley, New York: NY.

Hohenstein, N. O., Feisel, E., and Hartmann, E. (2014). Human resource management issues in supply chain management research: a systematic literature review from 1998 to 2014. International Journal of Physical Distribution \& Logistics Management, 44 (6), pp. 434-463.

Iacovou, C. L., Shirland, L., and Thompson, R. L. (2004). Job selection preferences of business students. Journal of Applied Business Research, 20 (1), pp. 87-98.

Ilgen, D., and Hollenbeck, J. (1991), "The structure of work: Job design and roles", In M. D. Dunnette, and L. M. Hough (Eds.), Handbook of Industrial and Organizational Psychology, Consulting Psychologists Press, Palo Alto, CA, pp. 165-208.

Jedidi, K., Kohli, R., and Desarbo, W. (1996). Consideration sets in conjoint analysis. Journal of Marketing Research, 33 (3), pp. 364-72.

Keller, S. B. (2002). Driver relationships with customers and driver turnover: Key mediating variables affecting driver performance in the field. Journal of Business Logistics, 23 (1), pp. 39-64.

Keller, S. B., and Ozment, J. (2009). Research on personnel issues published in leading logistics journals: What we know and don't know. International Journal of Logistics Management, 20 (3), pp. 378-407.

Knemeyer, A. M., and Murphy, P. R. (2004). Promoting the value of logistics to future business leaders: An exploratory study using a principles of marketing experience. International Journal of Physical Distribution and Logistics Management, 34 (10), pp. 775-786.

Jin, Y. H., Mjelde, J. W., and Litzenberg, K. K. (2014). Economic analysis of job-related attributes in undergraduate students' initial job selection. Education Economics, 22 (3), pp. 305327.

LeMay, S.A., Carr, J.C., Periatt, J.A. and McMahon Jr, R.D. (1999). The Growth and Development of Logistics Personnel. In Council of Logistics Management, Oak Brook, IL.

Lynagh, P. M., Murphy, P. R., and Poist, R. F. (1996). Career related perspectives regarding women in logistics: A comparative analysis. Transportation Journal, 36 (1), pp. 3542.

Lynagh, P. M., Murphy, P. R., and Poist, R. F. (1999). Career perspectives of women in distribution: congruency or contrast. International Journal of Physical Distribution and Logistics Management, 29 (3), pp. 192-207.
Maslow, A. H. (1943). A Theory of Human Motivation, Psychological Review, 50 (4), pp. 370-396.

Maloni, M. J., Scherrer, C. R., Campbell, S. M., and Boyd, E. (2016). Attracting students to the field of logistics, part 1. Transportation Journal, 55 (4), pp. 420-442.

Meyerding, S.G.H. (2017). Job preferences of agricultural students in Germany - A choice-based conjoint analysis for both genders. International Food and Agribusiness Management Review, $O(0)$, pp. $1-18$.

Ng, T., Eby, L., Sorensen, K., and Feldman, D. (2005). Predictors of objective and subjective career success: A meta-analysis. Personnel Psychology, 58 (2), pp. 367-408.

Oldham, G. R., and Hackman, R. J. (2010). Not what it was and not what it will be: The future of job design research. Journal of Organizational Behavior, 31 (2-3), pp. 463-479.

Ralston, P., LeMay, S., and Opengart, R. (2017). Factor Market Myopia: A Driver of Factor Market Rivalry. Transportation Journal, 56 (2), pp. 167-183.

Rice, R. W., Gentile, D. A., and McFarlin, D. B. (1991). Facet importance and job satisfaction. Journal of Applied Psychology, 76 (1), pp. 31-39.

Richey, R.G., Tokman, M., and Wheeler, A.R., (2006). A supply chain manager selection methodology: empirical test and suggested application. Journal of Business Logistics, 27 (2), pp. $163-190$

Sedighi, F., and Loosemore, M. (2012). Employer-of-choice characteristics in the construction industry. Construction Management and Economics, 30 (11), pp. 941-950.

Spector, P. E. (1985). Measurement of human services staff satisfaction: Development of the job satisfaction survey. American Journal of Community Psychology, 13 (6), pp. 693713.

Sullivan, S. E., and Arthur, M. B. (2006). The evolution of the boundaryless career concept: Examining physical and psychological mobility. Journal of Vocational Behavior, 69 (1), pp. 19-29.

Sullivan, S. E., and Baruch, Y. (2009). Advances in career theory and research: A critical review and agenda for future exploration. Journal of Management, 35 (6), pp. 1542-1571.

Super, D. (1957), Psychology of Careers, Harper and Brothers, New York, NY.

Tatham, P., Tatham, P., Wu, Y., Wu, Y., Kovács, G., Kovács, G., and Butcher, T. (2017). Supply chain management skills to sense and seize opportunities. The International Journal of Logistics Management, 28 (2), pp. 266-289.

Thatcher, J. B. (2002). Recruitment of information technology workers: Examining the influence of job seekers, organizations, and organizational agents (Order No 3055774). Doctoral Dissertation, Florida State University, Available from ABI/INFORM Collection. (251805452).

Vardi, Y. (1980). Organizational career mobility: An integrative model. Academy of Management Review, 5 (3), pp. 341-355.

Voss, M.D., Closs, D.J., Calantone, R.J., and Helferich, O. K. (2009). The role of security in the food supplier selection decision. The Journal of Business Logistics, 30(1), pp. 127-56.

Vroom, V. H. (1964), Work and motivation, New York: John Wiley and Sons.

Wolff, S. B., Wageman, R., and Fontaine, M. (2009). The coming leadership gap: An exploration of competencies that will be in short supply. International Journal of Human Resources Development and Management, 9 (2-3), pp. 250-274.

Yasmin, S., Mahmud, K., and Farzan Afrin, F. (2016). Job Attribute Preference of Executives: A Conjoint Analysis. Asian Social Science 12 (2), pp. 68-78. 
Michael S. Garver is Professor of Marketing at Central Michigan University. He earned his Ph.D. from the University of Tennessee, Knoxville. He stays active with the business community through speaking, consulting, and conducting best practice research. His interests include using leading edge methods in marketing and logistics. E-Mail: garve1ms@cmich.edu

Sean P. Goffnett is Associate Professor of Marketing and Logistics at Central Michigan University. He received his Ph.D. from Eastern Michigan University. His research interests include humanitarian logistics, leadership-followership, quality, process improvement, and talent management. E-Mail: sean.goffnett@cmich.edu

Richard L. Divine is Professor of Marketing at Central Michigan University. He earned his Ph.D. from Michigan State University. His primary research interests are marketing, buyer behavior, and business education. E-Mail: divin1rl@cmich.edu

Zachary Williams is Associate Professor of Marketing at Western Michigan University. He received his Ph.D. at Mississippi State University. His primary research interests are in the area of supply chain talent management and security in the supply chain. E-Mail: williamszchy@gmail.com

Connor F. Davis is an Export Analyst at Kimberly-Clark Corporation. Connor holds a Bachelor's of Science in Business Administration from Central Michigan University. E-Mail: davisfconnor@gmail.com 